\title{
Accounting
}

\section{Pricing model for Indonesia government bond}

\section{Randi Bayu Prathama ${ }^{a^{*}}$, Sugiarto ${ }^{b}$, Gracia Shinta S. Ugut ${ }^{\mathfrak{c}}$ and Edison Hulu ${ }^{d}$}

\author{
${ }^{a}$ Doctoral Program, Universitas Pelita Harapan, Indonesia \\ ${ }^{b}$ Faculty Member of Universitas Prasetiya Mulya, Indonesia \\ ${ }^{c}$ Faculty Member of Universitas Pelita Harapan, Indonesia \\ ${ }^{d}$ Lecturer, Universitas Pelita Harapan, Indonesia
}

\section{H R O N I C L E}

\section{Article history:}

Received May 152020

Received in revised format May

162020

Accepted July 62020

Available online

July 122020

Keywords:

Fair value price

Pricing model

Government bond

Dynamic model

\section{A B S T R A C T}

\begin{abstract}
The yield curve is the building block of fair value in pricing bonds. It has been used by market participants for their asset valuations, Central Bank and Government's Treasury for monetary, interest rate and borrowing decisions. The official yield curve construction in Indonesia government bond is based on Svensson model which is widely accepted and used by several countries. The objective is to find more accurate fair price from yield curve as the alternative of IBPA government bond curve as the baseline. This research takes observation on three alternative yield curve models in comparison with the baseline Svensson Model to price several series of benchmark and non-benchmark bonds. Fair price is further tested with One-Way ANOVA and Post Hoc in order to find the significance between models. The results show that alternative models are performing better in determining the fair value prices of the government bonds compared to the baseline model.
\end{abstract}

2020 by the authors; licensee Growing Science, Canada

\section{Introduction}

Bond market in Indonesia plays an important role in Indonesia overall economy. It is an integral part of Indonesia financial market in order to help to drive the economic growth. Government bond is not only traded on the primary market, but also on the secondary market. The existence of the secondary market provides liquidity and helps market participants manage their risk and return profile (Dajcman, 2015). While the primary market is the primary source of government budget funding, the secondary market provides liquidity for the investors. An active and liquid secondary market is one of positive signs signalling the economy is doing well (Caceres \& Unsal, 2013). In order to support both the primary and the secondary market, the yield curve and term structure of interest rate should be established. The yield curve of government bond plays a central role in pricing financial assets and form market expectation on the economy. It is also having great importance to build an accurate discount curve in order to give better fair price value forecast in the individual bonds as for the market reference. Therefore, accurately estimating and forecasting yield curve has great importance for Central Bank, government, fund managers, risk management and any other market participants. Accurately fitting the yield curve is an important topic in finance that has received considerable attention in past decade. There are three classes of curve fitting technique: The Spline method, parametric method and Nelson Siegel family method. Indonesia Bond Pricing Agency (IBPA) is the official body for government bond yield curve and fair price. They have done extensive effort and has been successfully led as the sole bond pricing and yield curve in Indonesia. However, due to generic Svensson model that has been widely used globally, IBPA has tighter opportunity to develop the generic model. In order to give better yield curve and fair price valuation for government bond market, we developed several

* Corresponding author

E-mail address: RP8519@student.uph.edu (R. B. Prathama) 
models so it could improve the official pricing performance and therefore it would support the development of Indonesia bond market.

The objective is to propose yield curve as the alternative of official government bond curve from IBPA. We hope the result of this research will give direct contributions to market participants for their asset valuations, Central Bank and Government's Treasury for monetary, interest rate and borrowing decisions.

\section{Theoretical Framework}

\subsection{Spline method}

The first well known method in modelling the yield curve is Spline method. It is arranged by the piecewise polynomial method (or also called the spline function), when there are several individual segments arranged together. The initial Spline method was developed by the cubic spline method (McCulloch, 1971; McCulloch, 1975) when the yield curve of the zero-coupon bond is divided into several intervals. They developed a yield curve modelling technique using the smooth curve fitting method called the "discount function". The basic model was further developed into the modification of exponential part of the discount function so that the bond data could be used properly where the data is the main basis of forming curves (Vasicek \& Fong, 1982). Fisher, Nyckha and Zervos (FNZ) developed a better technique for smoothing the spline curve with including the penalty factor of "excess roughness" in the extraction of forward rate curves. The roughness penalty factor is used as a constant for all maturities so that the results of the spline become firmer or in other words reduce the possibility of swinging (Fisher, et al., 1995).

\subsection{Parametric method}

The other research of the equilibrium theory on interest rates was first developed by Vasicek in 1977. The term structure of interest rate regulates the relationship between the yields of default free bonds that have different maturity schedules. Further research was developed by Cox, Ingersoll and Rand (CIR) in 1985. CIR approached the rational price valuation of assets to study the term structure. With this research, CIR provides a simple solution which involves various economic variables. CIR research is useful in its application for European bonds and call options (Cox, et al., 1985). Further development was carried out by John Hull and Alan White in 1990. Research based on the one-state-variable Vasicek and CIR models can be extended so that they can be consistent both for the term structure of interest rate, spot interest rate volatility and for forward interest volatility rate (Hull \& White, 1990). Subsequent research was conducted by David Heath, Robert Jarrow and Andrew Morton in 1992. The focus of this research is a new method for solving problems of assessing interest rate contingent claims from various zero-coupon bonds. The fundamental difference between this method and the CIR method in contingent claim valuation on the yield curve is that this model uses an existing forward rate curve and the arbitrage price valuation is built with that curve. Thus, this model does not depend on market risk factors (Heath, et al., 1992).

\subsection{Nelson Siegel model (1987)}

Nelson and Siegel introduced a simple Parsimonius model which can adapt easily to the range of shapes of yield curves (ie flat, humped and S shape). The main benefit of Nelson Siegel model is the simplicity and therefore it is widely accepted by central banks and market practitioners. The model is formulated as follows:

$f_{m}=\beta_{1}+\beta_{2} \exp \left(\frac{-m}{\tau_{1}}\right)+\beta_{3} \frac{m}{\tau_{1}} \exp \left(\frac{-m}{\tau_{1}}\right)$

where $\boldsymbol{f}_{\boldsymbol{m}}$ is the forward rate under NS model, $\boldsymbol{\beta}_{\mathbf{1}}, \boldsymbol{\beta}_{\mathbf{2}}$, and $\boldsymbol{\beta}_{\mathbf{3}}$ are the linear parameters where each describes long term component, short term component and medium term component and $\boldsymbol{\tau}$ as the parameter of maturity. The forward rate equation can be different equation depending on the parameters' value, therefore spot rate $\left(\boldsymbol{S}_{\boldsymbol{m}}\right)$ is obtained:

$S_{m}=\beta_{1}+\beta_{2} \frac{1-\exp \left(\frac{-m}{\tau_{1}}\right)}{\frac{m}{\tau_{1}}}+\beta_{3}\left(\frac{1-\exp \left(\frac{-m}{\tau_{1}}\right)}{\frac{m}{\tau_{1}}}-\exp \left(\frac{-m}{\tau_{1}}\right)\right)$

For long maturity dates, spot and forward rate on the value of $\boldsymbol{\beta}_{\mathbf{1}}$ must have a positive value. The sum of the first two factors, namely $\boldsymbol{\beta}_{\mathbf{1}}$ and $\boldsymbol{\beta}_{\mathbf{2}}$ must also have a positive value since it determines the initial value of the curve when the initial due date. The next parameter is $\boldsymbol{\beta}_{\mathbf{3}}$ and $\boldsymbol{\tau}_{\mathbf{1}}$ are "hump", where the value of $\boldsymbol{\beta}_{\mathbf{3}}$ determines the amount of hump and the direction is determined by a negative value that indicates the form U-shapes and a negative value indicates the form of a hump.

\subsection{Svensson model (1994)}

The next model was developed by Svensson (1994) to increase the flexibility of curve and curve point accuracy. The model was developed from Nelson Siegel's original model by adding an extra exponential term to increase the fit and flexibility of the yield 
curve. This extra term provides the capability of possible hump in the yield curve. The spot rate that formulated as follows (Svensson, 1994):

$S_{m}=\beta_{1}+\beta_{2} \frac{1-\exp \left(\frac{-m}{\tau_{1}}\right)}{\frac{m}{\tau_{1}}}+\beta_{3}\left(\frac{1-\exp \left(\frac{-m}{\tau_{1}}\right)}{\frac{m}{\tau_{1}}}-\exp \left(\frac{-m}{\tau_{1}}\right)\right)+\beta_{4}\left(\frac{1-\exp \left(\frac{-m}{\tau_{2}}\right)}{\frac{m}{\tau_{2}}}-\exp \left(\frac{-m}{\tau_{2}}\right)\right)$.

The component $\boldsymbol{\beta}_{\mathbf{4}}$ is the second hump and decay parameter $\boldsymbol{\tau}_{\mathbf{2}}$ is a time constant which is positive and determines the location of possible second hump in the yield curve.

\subsection{Diebold-Li model (2006)}

This development was introduced by Diebold and Li in 2006 when they were introducing the dynamic Nelson Siegel model. The main purpose of this development is to get better fit on the yield curve, especially in the longer term of the curve. It was obtained by reparametrizing the original formulation the yield $\boldsymbol{S}_{m}\left(\boldsymbol{\tau}_{1}\right)$ as a function of three parameters (Level or long-term factor, Slope or short-term factor and Curvature or medium-term factor) and one $\lambda$ that determines the maturity at which the loading of Curvature will be maximized (Diebold \& Li, 2006).

$S_{m}\left(\tau_{1}\right)=L_{t}+S_{t}\left(\frac{1-e^{-\lambda \tau_{1}}}{\lambda \tau_{1}}\right)+C_{t}\left(\frac{1-e^{-\lambda \tau_{1}}}{\lambda \tau_{1}}-e^{-\lambda \tau_{1}}\right)+\varepsilon_{i, m}$

whereby:

$$
\begin{array}{ll}
\boldsymbol{y}_{\boldsymbol{m}}=\text { denotes the set of spot yield curve } & \boldsymbol{S}_{\boldsymbol{t}}=\text { slope } \\
\boldsymbol{\tau}_{\mathbf{1}}=\text { corresponding maturity } & \boldsymbol{C}_{\boldsymbol{t}}=\text { curvature } \\
\boldsymbol{L}_{\boldsymbol{t}}=\text { level } & \boldsymbol{\lambda}=\text { lambda, set fixed }
\end{array}
$$

Further research by Diebold, Rudebusch and Aruoba (DRA) in 2007 suggested to frame the Diebold Li model can be framed in state space model where the three factors are treated as unobserved processes and modelled by vector autoregressive process. The process in DNS model under DRA relies on two simplification assumptions:

1. The factor loading $(\lambda)$ is keep constant over time which is set in value 0.077 following DRA model

2. Variance $(\boldsymbol{\varepsilon})$ is keep constant for all maturities of the time series (Diebold \& Li, 2006; Diebold, et al., 2007)

However, set the $\lambda$ fixed over the full period of research will be too restrictive and however the fixed value was based on US market which considered as much more liquid than Indonesia bond market.

\subsection{Fair Price Valuation}

Bond price is valued by discounting the future cashflow, which includes the contractual coupon and the principal. The coupon bonds can be replicated as for a portfolio holding of zero-coupon bonds with maturities of $i=1, \ldots, n$. By using spot rate as a discount factor, the fair price of a bond can be determined. Below is the basic formulation on the bond price using the different $r$ or discount factor:

Price $=\sum_{i=1}^{n} \frac{\text { Coupon }}{(i+r)^{i}}+\frac{\text { Principal }}{(i+r)^{n}}$

However, the bond price is not quoted as cash price, the quoted price in the market is the clean price (which exclude the accrued interest). Accrued interest is the interest accumulated between the most recent coupon payment and the present time. The formula of accrued interest as below:

Accrued Interest $=C\left(\frac{t_{0}-t_{p}}{t_{q}-t_{p}}\right)$,

whereby $t_{0}$ is current time, $t_{p}$ for previous date of coupon payment and $t_{q}$ is the next date of coupon payment. Therefore, the bond's quoted price is as below:

Quoted price $=$ Price - Accrued Interest

\section{Research method}

For the purpose of this research, it was necessary to obtain daily parameters from January 2014 until December 2019 which provides 1150 periods. A term structure was constructed using the aforementioned data which 30 expirations were determined: $1,2,3,4,5,6,7,8,9,10,11,12,13,14,15,16,17,18,19,20,21,22,23,24,25,27,27,28,29$ and 30 years of Indonesia 
government yield. All information were obtained from Bloomberg terminal platform. There were approximately 38,190 yield data during 2014 to 2019 period that will be treated as data input for the three model under this research. The model building was coded into Matlab that have differences on the formula, linearity and non-linearity. Ten series bonds were selected under this research that are considered series of benchmark bonds and non-benchmark bonds to see the fair price valuation on each proposed model:

\section{Table 1}

Information on bond series of Indonesia government bond

\begin{tabular}{|c|c|c|c|c|c|c|c|c|}
\hline No & Series & Issue Date & Maturity Date & Maturity & Coupon & $\begin{array}{l}\text { Nominal } \\
\text { (IDR tn) }\end{array}$ & $\begin{array}{l}\text { Trading Vol } \\
\text { (IDR tn) }\end{array}$ & Turnover Ratio \\
\hline 1 & FR0059 & 15-Sep-11 & 15-May-27 & 8.49 & $7.00 \%$ & 115 & 415 & $419.30 \%$ \\
\hline 2 & FR0064 & 13-Aug-12 & 15-May-28 & 9.51 & $6.13 \%$ & 91 & 339 & $180.60 \%$ \\
\hline 3 & FR0074 & 10-Nov-16 & 15-Aug-32 & 13.82 & $7.50 \%$ & 44 & 264 & $546.20 \%$ \\
\hline 4 & FR0072 & 09-Jul-15 & 15-May-36 & 17.63 & $8.25 \%$ & 89 & 289 & $372.60 \%$ \\
\hline 5 & FR0061 & 06-Oct-11 & 15-May-22 & 3.42 & $7.00 \%$ & 99 & 302 & $305.80 \%$ \\
\hline 6 & FR0043 & 22-Feb-07 & 15-Jul-22 & 3.59 & $10.25 \%$ & 14 & 4 & $18.30 \%$ \\
\hline 7 & FR0039 & 24-Aug-06 & 15-Aug-23 & 4.69 & $11.75 \%$ & 4 & 1 & $11.50 \%$ \\
\hline 8 & FR0037 & 18-May-06 & 15-Sep-26 & 7.82 & $12.00 \%$ & 2 & 1 & $20.50 \%$ \\
\hline 9 & FR0045 & 24-May-07 & 15-May-37 & 18.64 & $9.75 \%$ & 10 & 2 & $13.70 \%$ \\
\hline 10 & FR0050 & 24-Jan-08 & 15-Jul-38 & 19.82 & $10.50 \%$ & 16 & 4 & $6.30 \%$ \\
\hline
\end{tabular}

Under this research, there are three proposed model to be in comparison with the baseline which are the official Indonesia yield curve:

\subsection{Dynamic Nelson Siegel (Model 1)}

The model is based on Diebold Li research in 2006 that reparametrizing the original formulation the yield spot rate into three simple parameters level, slope and curvature as already discussed in B.5. The lambda is set at 0.077 following DRA model. The observation on fair price valuation based on Diebold Li model is an interesting step since the official yield curve is currently using Svensson model. Therefore, the result would give valuable insight on the alternative model.

\subsection{Dynamic Nelson Siegel with Time Varying Loading Parameter (Model 2)}

The second model was based on the extension of Diebold Li and state space representation by Diebold, Rudebusch and Aruouba (2007). In the first model, to set the $\lambda$ fixed at 0.077 (or 23.3 months) was too restrictive and based on US market which were also considered as much more liquid compared to Indonesia bond market.

Therefore, formulating the Diebold Li under state-space representation under Diebold, Rudebusch and Aruouba suggestion would enable the $\lambda$ as adaptive as possible (Castaño, et al., 2014). The $\lambda$ was treated as fourth latent factor and consequently the factors $\boldsymbol{\beta}_{\boldsymbol{t}}$ become 4 x 1 vector. The new model was now become non-linear due to the interaction between the loading factor and the level, slope and curvature factors in the time series. To solve the non-linearity problem, the extended Kalman Filter was used. The yield curve function as below:

$S_{m}\left(\tau_{1}\right)=L_{t}+S_{t}\left(\frac{1-e^{-\lambda \tau_{1}}}{\lambda \tau_{1}}\right)+C_{t}\left(\frac{1-e^{-\lambda \tau_{1}}}{\lambda \tau_{1}}-e^{-\lambda \tau_{1}}\right)+\varepsilon_{i, m}$

whereby:

$$
\begin{array}{ll}
\boldsymbol{S}_{\boldsymbol{m}}=\text { denotes the set of spot yield curve } & \boldsymbol{S}_{\boldsymbol{t}}=\text { slope } \\
\boldsymbol{\tau}_{\mathbf{1}}=\text { corresponding maturity } & \boldsymbol{C}_{\boldsymbol{t}}=\text { curvature } \\
\boldsymbol{L}_{\boldsymbol{t}}=\text { level } & \boldsymbol{\lambda}=\text { lambda, set dynamic based on rolling last } 200 \text { trading days }
\end{array}
$$

The $\lambda$ and above function were based on rolling last 200 trading days (approximately one-year trading activity) in order to find the best fit of the model that will vary over time (or Time Varying)

\subsection{Dynamic Nelson Siegel Svensson with Time Varying Loading Parameter (Model 3)}

The third model was the combination of the original Svensson (1994), Diebold and Li (2006) and Diebold, Rudebusch and Aruouba (2007) model. The yield curve adds a second curvature term with allows more flexibility and a better in-sample fit at longer maturities. The authors would like to propose this new model development due to combination of well accepted Svensson model and the $\lambda$ dynamic that can adapt on the latest situation in the bond market. 
This model had the same non linearity problem with the second model, therefore the same state space representation and extended Kalman Filter are applied to solve the problem. The yield curve function as below:

$S_{m}(\tau)=L_{t}+S_{t}\left(\frac{1-e^{-\lambda_{1} \tau}}{\lambda_{1} \tau}\right)+C_{1}\left(\frac{1-e^{-\lambda_{1} \tau}}{\lambda_{1} \tau}-e^{-\lambda_{1} \tau}\right)+C_{2}\left(\frac{1-e^{-\lambda_{2} \tau_{1}}}{\lambda_{2} \tau}-e^{-\lambda_{2} \tau}\right)+\varepsilon_{i, m}$

whereby:

$$
\begin{aligned}
& \boldsymbol{S}_{\boldsymbol{m}}=\text { denotes the set of spot yield curve } \\
& \boldsymbol{\tau}_{\mathbf{1}}=\text { corresponding maturity } \\
& \boldsymbol{L}_{\boldsymbol{t}}=\text { level } \\
& \boldsymbol{S}_{\boldsymbol{t}}=\text { slope }
\end{aligned}
$$$$
\boldsymbol{C}_{\mathbf{1}}=\text { first curvature }
$$$$
\boldsymbol{C}_{\mathbf{1}}=\text { second curvature }
$$$$
\lambda_{1}=\text { first lambda, set dynamic based on rolling last } 200 \text { trading days }
$$$$
\lambda_{2}=\text { second lambda, set dynamic based on rolling last } 200 \text { trading days }
$$

In fact, that the model had second Curvature and Lambda, the model had more flexibility in the yield curve modelling especially in the longer curve therefore will give benefit on the less liquid bond that usually situated on longer maturity. The second lambda or decay factor costs the model high degree of multicollinearity between factors (Bolder \& Stréliski, 1999). The problem arises when the decay factor assumes similar values therefore making it hard to identify the first and second Curvature. To solve this issue, we follow De Pooter (2007) suggestion to give minimum distance between factors which $\lambda_{1} \geq \lambda_{2}+6.69$. The model was processed base on rolling last 200 trading days (or approximately one-year trading activity). The rolling periods were to find the best fit and to be adaptive with the latest situation on the Indonesia economy and the bond market.

\section{Results and discussion}

To compare the fair price between four yield curves that derived from four models, descriptive statistic was used to observe the pricing performance. Each model will be compared with actual trading data. The comparative statistics are average absolute error, mean average error, root mean square error and standard deviation. Fig. 1, Fig. 2 and Fig. 3 show the result of level, slope and curvature plus additional curvature and lambda for Model 2 and Model 3. The result of lambda, level, slope and curvature are the backbone of yield curve construction on each trading day and maturity schedule so that we will have three alternate curve and baseline curve as the main spot rate input for fair price bond valuations. Fair price result for ten government bond series as shown in Figs. 4-7 and Fig. 8 for benchmark series and Figs. 9-13 for non-benchmark series.
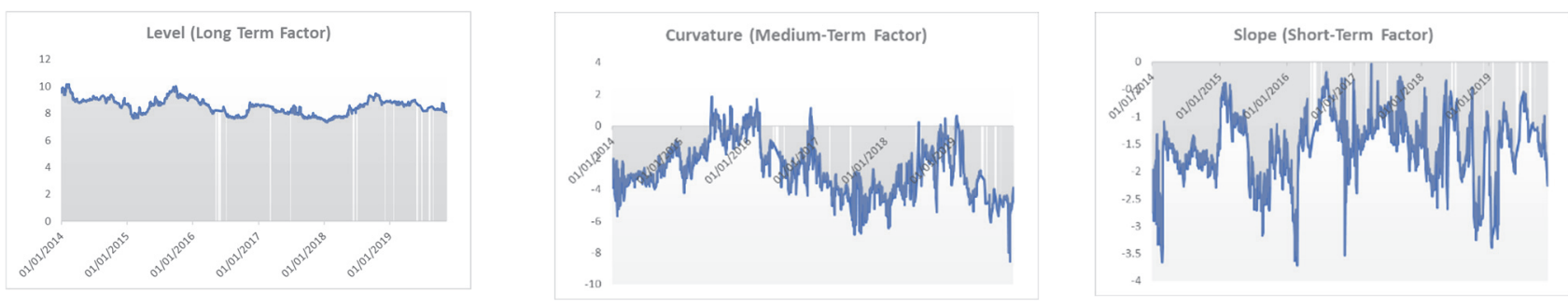

Fig. 1. Model 1 result (level, slope \& curvature)
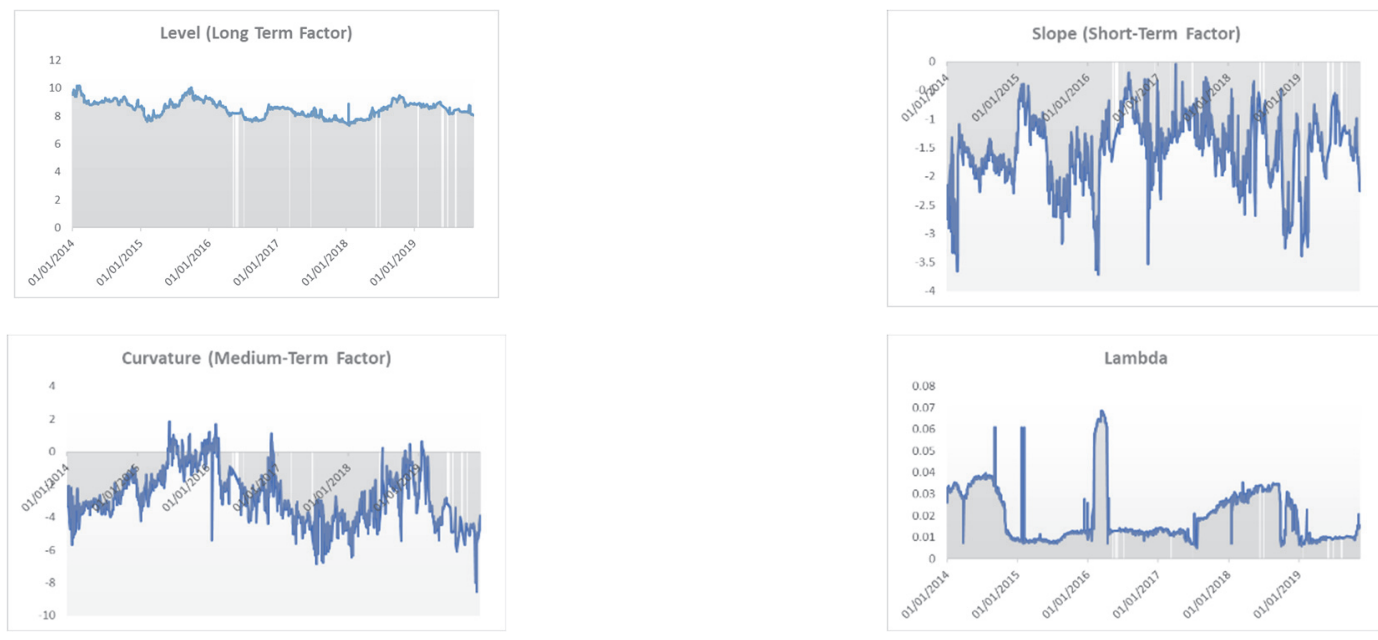

Fig. 2. Model 2 result (level, slope, curvature) 

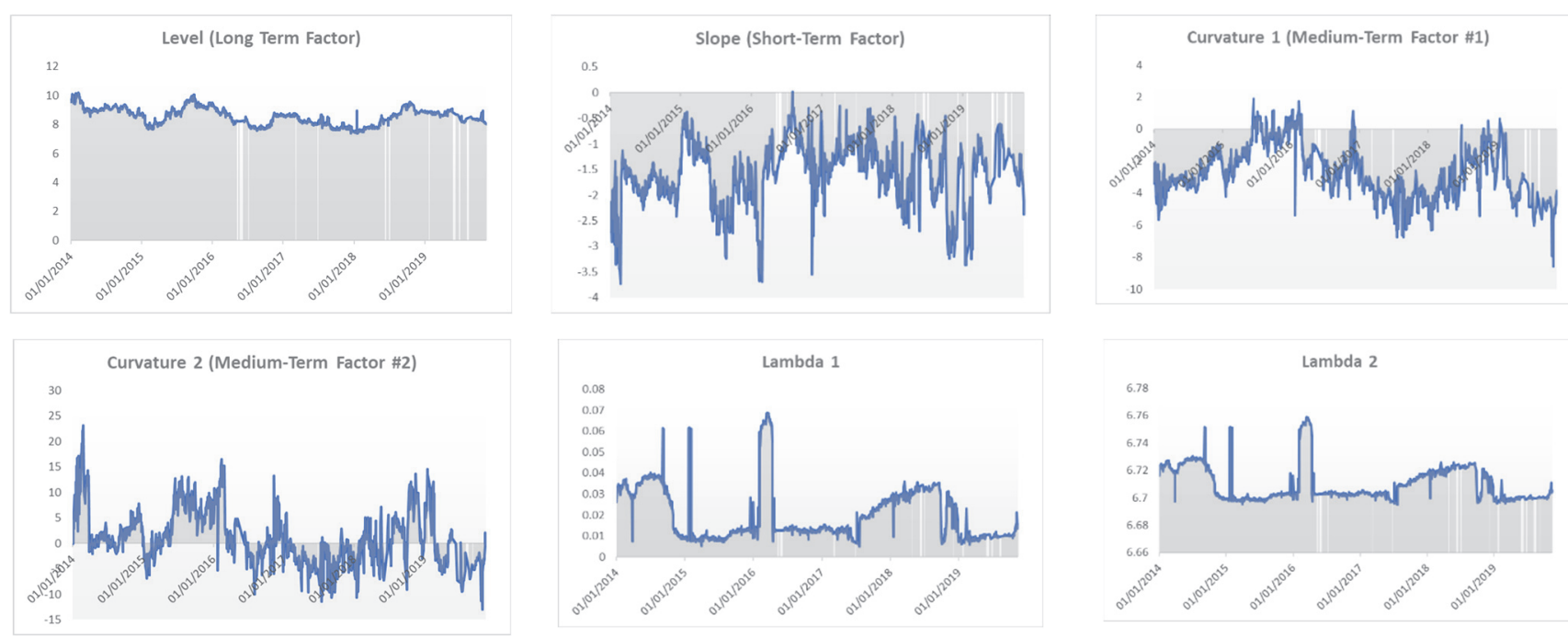

Fig. 3. Model 3 result (level, slope, curvature 1, curvature 2, lambda $1 \&$ lambda 2)

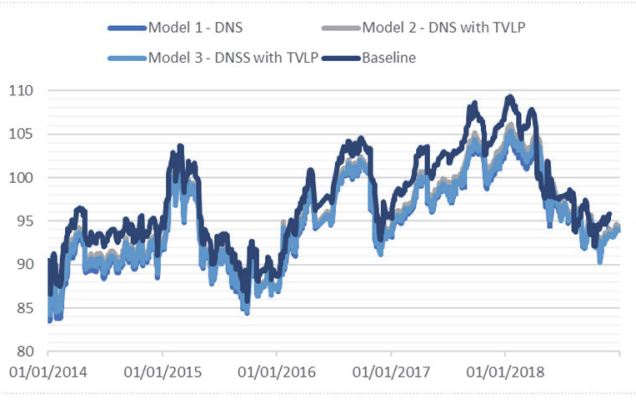

Fig. 4. Fair price result comparison for FR0059

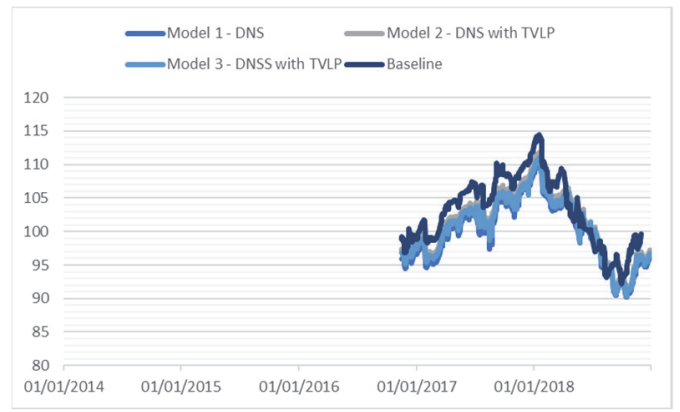

Fig. 6. Fair price result comparison for FR0074

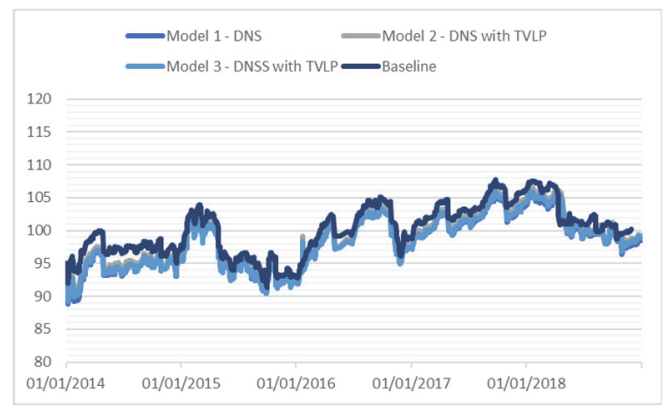

Fig. 8. Fair price result comparison for FR0061

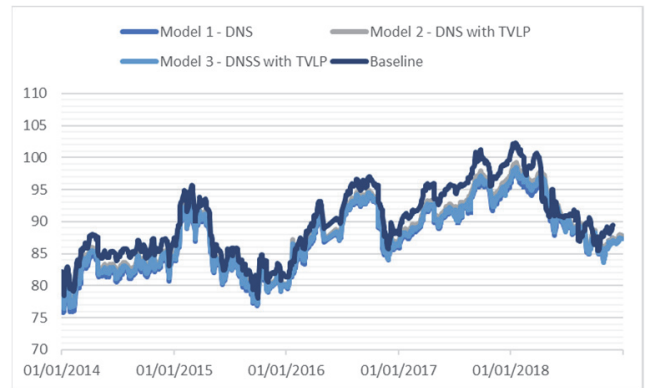

Fig. 5. Fair price result comparison for FR0064

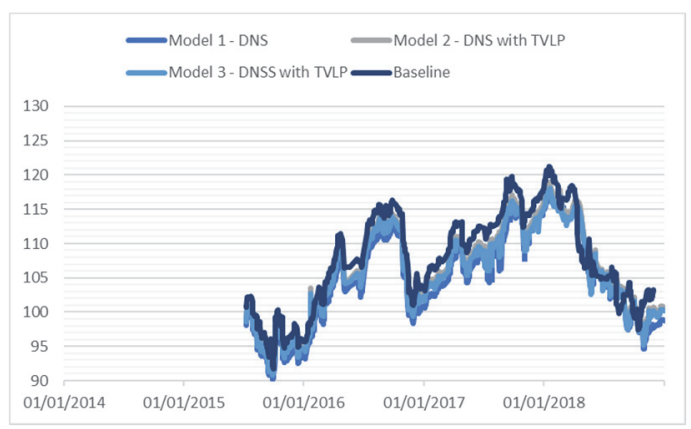

Fig. 7. Fair price result comparison for FR0072

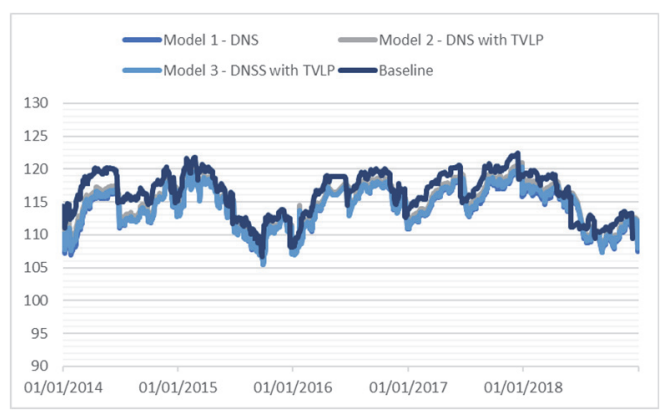

Fig. 9. Fair price result comparison for FR0043 


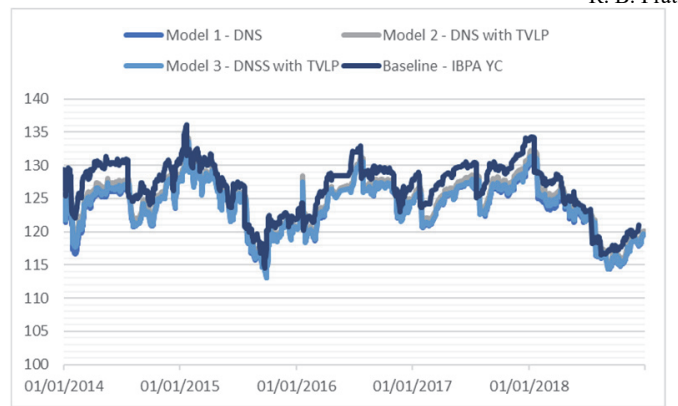

Fig. 10. Fair price result comparison for FR0039

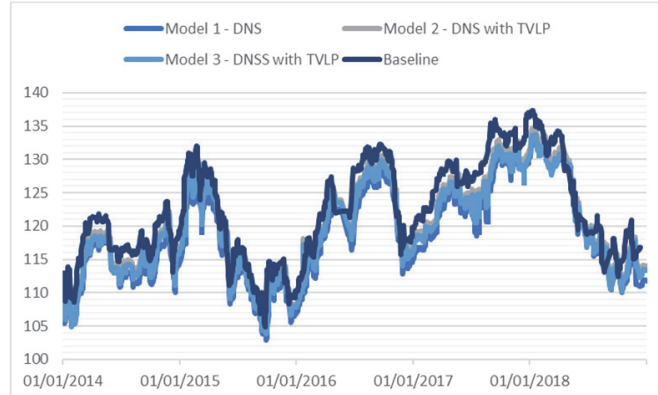

Fig. 12. Fair price result comparison for FR0045

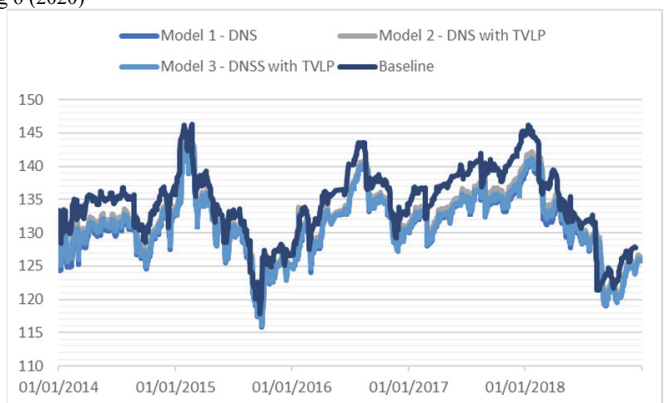

Fig. 11. Fair price result comparison for FR0037

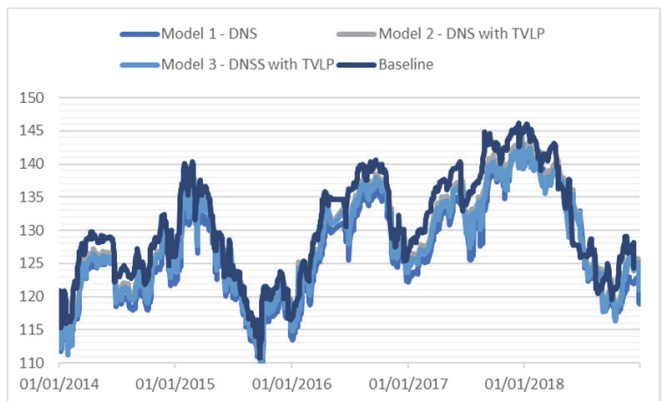

Fig. 13. Fair price result comparison for FR0050

The fair price from Fig. 4 to Fig. 13 further was compared with the actual trading price in order to see the backward or in-sample pricing performance. Therefore, fair price from each model was to be tracked on error or discrepancies between empirical price and actual price on daily basis. The descriptive result that are shown in Table 2, 3, 4 and 5 respectively demonstrate the average absolute error, root mean square error, mean average error and standard deviation. As we see from four statistics, Model 1, 2 and 3 resulted better compared to the baseline except for Model 2 on FR0074 and FR0072. Model 1 or based on the original Diebold Li (2006) performed better than all model followed by Model 3 that is proposed under this research. As also shown in Table 5, Model 1 also provided better stability of the tracking error with the standard deviations are much less than the other models.

Table 2

Average Absolute Error Result

\begin{tabular}{|c|c|c|c|c|}
\hline Series & DNS & DNS with TVLP & DNSS with TVLP & Baseline \\
\hline FR0059 & 1.37 & 1.74 & 1.52 & 2.37 \\
\hline FR0064 & 1.28 & 1.74 & 1.49 & 2.54 \\
\hline FR0074 & 1.49 & 2.17 & 1.73 & 1.69 \\
\hline FR0072 & 2.29 & 3.53 & 2.99 & 3.46 \\
\hline FR0061 & 1.12 & 1.49 & 1.17 & 1.67 \\
\hline FR0043 & 1.95 & 2.51 & 2.04 & 2.82 \\
\hline FR0039 & 2.26 & 2.84 & 2.35 & 3.45 \\
\hline FR0037 & 2.53 & 3.28 & 2.75 & 3.95 \\
\hline FR0045 & 4.32 & 5.94 & 5.34 & 6.07 \\
\hline FR0050 & 4.9 & 6.66 & 6.02 & 6.88 \\
\hline
\end{tabular}

Table 3

Root Mean Square Error Result

\begin{tabular}{|c|c|c|c|c|}
\hline Series & DNS & DNS with TVLP & DNSS with TVLP & Baseline \\
\hline FR0059 & 1.63 & 2.05 & 1.82 & 2.93 \\
\hline FR0064 & 1.49 & 2.02 & 1.75 & 3.09 \\
\hline FR0074 & 1.13 & 1.61 & 1.32 & 2.86 \\
\hline FR0072 & 2.26 & 3.12 & 2.71 & 4.54 \\
\hline FR0061 & 1.35 & 1.73 & 1.4 & 2.27 \\
\hline FR0043 & 2.29 & 2.79 & 2.38 & 3.5 \\
\hline FR0039 & 2.7 & 3.22 & 2.78 & 4.21 \\
\hline FR0037 & 3.18 & 3.9 & 3.41 & 4.99 \\
\hline FR0045 & 4.75 & 6.17 & 5.6 & 7.15 \\
\hline FR0050 & 5.28 & 6.83 & 6.21 & 7.96 \\
\hline
\end{tabular}


1090

Model 1 shows consistency in in-sample observation for both benchmark and non-benchmark series compared with other models. Better result shows a probability that the development of Neslon Siegel by Diebold Li in 2016 provides a simple yet accurate result since it directly produced level, slope and curvature with the $\lambda$ held fixed at 0.077 or 23.3 months. However, the Model 3 shows also consistency on the result as the second-best performance. The model was a combination between original Svensson, DNS and DRA model with the difference was on the $\lambda$ treated as dynamic factor. Additional hump on the third model has proved that it performed better than the second model that only has one hump.

Table 4

Mean Average Error Result

\begin{tabular}{ccccc}
\hline Series & DNS & DNS with TVLP & DNSS with TVLP & Baseline \\
\hline FR0059 & 1.33 & 1.69 & 1.48 & 2.37 \\
FR0064 & 1.24 & 1.69 & 1.45 & 2.54 \\
FR0074 & 0.59 & 0.86 & 0.68 & 1.69 \\
FR0072 & 1.49 & 2.29 & 1.94 & 3.46 \\
FR0061 & 1.09 & 1.45 & 1.14 & 1.67 \\
FR0043 & 1.84 & 2.37 & 1.93 & 2.82 \\
FR0039 & 2.15 & 2.71 & 2.25 & 3.45 \\
FR0037 & 2.47 & 3.2 & 2.69 & 3.95 \\
FR0045 & 4.22 & 5.79 & 5.21 & 6.07 \\
FR0050 & 4.78 & 6.49 & 5.87 & 6.88 \\
\hline
\end{tabular}

Table 5

Standard Deviation Result

\begin{tabular}{ccccc}
\hline Series & DNS & DNS with TVLP & DNSS with TVLP & Baseline \\
\hline FR0059 & 0.94 & 1.15 & 1.06 & 1.72 \\
FR0064 & 0.83 & 1.11 & 0.99 & 1.77 \\
FR0074 & 0.96 & 1.37 & 1.13 & 2.31 \\
FR0072 & 1.7 & 2.12 & 0.81 & 2.94 \\
FR0061 & 0.79 & 0.94 & 1.39 & 1.55 \\
FR0043 & 1.36 & 1.47 & 1.63 & 2.07 \\
FR0039 & 1.62 & 1.74 & 2.1 & 2.41 \\
FR0037 & 2.01 & 2.23 & 2.05 & 3.05 \\
FR0045 & 2.19 & 2.14 & 2.02 & 3.79 \\
FR0050 & 2.25 & 2.12 & 4.01 \\
\hline
\end{tabular}

To see the significance of those models, we used Analysis of Variance (ANOVA). One-way ANOVA is a parametric test that compares means from four models in order to determine whether there was any statistical evidence that associated population means are significantly different. We performed one-way ANOVA on absolute error between each model compared to actual traded price. All ANOVA output in Table 6 have shown high significance at 0.000 therefore, all models are statistically different.

Table 6

One-way ANOVA Test

\begin{tabular}{|c|c|c|c|c|c|}
\hline Series & $\mathbf{F}$ & Sig. & Series & $\mathbf{F}$ & Sig. \\
\hline FR0059 & 512.296 & $0.000 *$ & FR0043 & 343.949 & $0.000 *$ \\
\hline FR0064 & 809.364 & $0.000^{*}$ & FR0039 & 356.837 & $0.000 *$ \\
\hline FR0074 & 463.349 & $0.000 *$ & FR0037 & 370.123 & $0.000 *$ \\
\hline FR0072 & 462.473 & $0.000 *$ & FR0045 & 406.939 & $0.000 *$ \\
\hline FR0061 & 445.346 & $0.000 *$ & FR0050 & 462.615 & $0.000 *$ \\
\hline
\end{tabular}

*. The mean difference is significant at the 0.05 level

The next verification step was to perform Post Hoc Test. We took Tukey HSD (Honestly Significant Difference) in Table 7 test to check pair of groups (or model) that are statistically different at 0.05 . We could see all pairs are statistically significant at 0.05 except for pair Model 1 and Model 3 in FR0061, FR0043, FR0039 and FR0037. We took further checking with LSD (Least Significant Difference) test in Table 8 to test the smallest significant between two groups as opposed to all group together. This could be the case of time to maturity since all four series are less than 8 years to mature (i.e. 3.5 year, 4.7 year and 7.8 year). The maturity effect has connection with the term structure of liquidity, i.e. liquidity premium exists mostly at relatively short maturities (Krishnamurthy \& Jorgensen, 2012). 
Table 7

Post Hoc Tukey Honestly Significant Difference (HSD) Test

\begin{tabular}{|c|c|c|c|c|c|c|}
\hline \multicolumn{2}{|c|}{ Significance } & \multirow{2}{*}{$\begin{array}{c}\text { FR0059 } \\
\text { Tukey HSD }\end{array}$} & \multirow{2}{*}{$\begin{array}{c}\text { FR0064 } \\
\text { Tukey HSD }\end{array}$} & \multirow{2}{*}{$\begin{array}{c}\text { FR0074 } \\
\text { Tukey HSD }\end{array}$} & \multirow{2}{*}{$\begin{array}{c}\text { FR0072 } \\
\text { Tukey HSD }\end{array}$} & \multirow{2}{*}{$\begin{array}{c}\text { FR0061 } \\
\text { Tukey HSD }\end{array}$} \\
\hline Model & Model & & & & & \\
\hline \multirow{3}{*}{1} & 2 & $0.000^{*}$ & $0.000 *$ & $0.000^{*}$ & $0.000^{*}$ & $0.000^{*}$ \\
\hline & 3 & $0.006^{*}$ & $0.000 *$ & $0.029 *$ & $0.000^{*}$ & 0.95 \\
\hline & 4 & $0.000 *$ & $0.000 *$ & $0.000 *$ & $0.000^{*}$ & $0.000 *$ \\
\hline \multirow{3}{*}{2} & 1 & $0.000^{*}$ & $0.000^{*}$ & $0.000^{*}$ & $0.000^{*}$ & $0.000 *$ \\
\hline & 3 & $0.000 *$ & $0.000 *$ & $0.000 *$ & $0.000 *$ & $0.000 *$ \\
\hline & 4 & $0.000 *$ & $0.000 *$ & $0.000^{*}$ & $0.000 *$ & $0.000 *$ \\
\hline \multirow{3}{*}{3} & 1 & $0.006^{*}$ & $0.000 *$ & $0.029 *$ & $0.000^{*}$ & 0.95 \\
\hline & 2 & $0.000 *$ & $0.000 *$ & $0.000^{*}$ & $0.000 *$ & $0.000 *$ \\
\hline & 4 & $0.000^{*}$ & $0.000^{*}$ & $0.000^{*}$ & $0.000^{*}$ & $0.000 *$ \\
\hline \multirow{3}{*}{4} & 1 & $0.000 *$ & $0.000^{*}$ & $0.000 *$ & $0.000^{*}$ & $0.000^{*}$ \\
\hline & 2 & $0.000 *$ & $0.000^{*}$ & $0.000^{*}$ & $0.000 *$ & $0.000 *$ \\
\hline & 3 & $0.000^{*}$ & $0.000 *$ & $0.000 *$ & $0.000^{*}$ & $0.000 *$ \\
\hline \multicolumn{2}{|c|}{ Significance } & FR0043 & FR0039 & FR0037 & FR0045 & FR0050 \\
\hline \multirow{3}{*}{1} & 2 & $0.000^{*}$ & $0.000 *$ & $0.000 *$ & $0.000 *$ & $0.000 *$ \\
\hline & 3 & 0.769 & 0.948 & 0.572 & $0.000 *$ & $0.000 *$ \\
\hline & 4 & $0.000 *$ & $0.000^{*}$ & $0.000 *$ & $0.000^{*}$ & $0.000 *$ \\
\hline \multirow{3}{*}{2} & 1 & $0.000^{*}$ & $0.000 *$ & $0.000 *$ & $0.000 *$ & $0.000 *$ \\
\hline & 3 & $0.000 *$ & $0.000 *$ & $0.000 *$ & $0.000^{*}$ & $0.000 *$ \\
\hline & 4 & $0.000 *$ & $0.000^{*}$ & $0.000 *$ & $0.000 *$ & $0.000 *$ \\
\hline \multirow{3}{*}{3} & 1 & 0.769 & 0.948 & 0.572 & $0.000^{*}$ & $0.000^{*}$ \\
\hline & 2 & $0.000 *$ & $0.000 *$ & $0.000 *$ & $0.000 *$ & $0.000 *$ \\
\hline & 4 & $0.000^{*}$ & $0.000^{*}$ & $0.000^{*}$ & $0.000^{*}$ & $0.000 *$ \\
\hline \multirow{3}{*}{4} & 1 & $0.000^{*}$ & $0.000 *$ & $0.000 *$ & $0.000^{*}$ & $0.000^{*}$ \\
\hline & 2 & $0.000 *$ & $0.000^{*}$ & $0.000 *$ & $0.000^{*}$ & $0.000 *$ \\
\hline & 3 & $0.000^{*}$ & $0.000 *$ & $0.000^{*}$ & $0.000^{*}$ & $0.000^{*}$ \\
\hline
\end{tabular}

*. The mean difference is significant at the 0.05 level

Table 8

Post Hoc Least Significant Difference (LSD) Test

\begin{tabular}{|c|c|c|c|c|c|}
\hline \multicolumn{2}{|c|}{ Significance } & FR0061 & FR0043 & FR0039 & FR0037 \\
\hline Model & Model & LSD & LSD & LSD & LSD \\
\hline \multirow{3}{*}{1} & 2 & $0.000 *$ & $0.000 *$ & $0.000 *$ & $0.000 *$ \\
\hline & 3 & 0.591 & 0.334 & 0.585 & 0.198 \\
\hline & 4 & $0.000 *$ & $0.000 *$ & $0.000 *$ & $0.000 *$ \\
\hline \multirow{3}{*}{2} & 1 & $0.000^{*}$ & $0.000 *$ & $0.000 *$ & $0.000 *$ \\
\hline & 3 & $0.000 *$ & $0.000 *$ & $0.000 *$ & $0.000 *$ \\
\hline & 4 & $0.000 *$ & $0.000 *$ & $0.000 *$ & $0.000 *$ \\
\hline \multirow{3}{*}{3} & 1 & 0.591 & $0.334^{*}$ & 0.585 & 0.198 \\
\hline & 2 & $0.000 *$ & $0.000 *$ & $0.000 *$ & $0.000 *$ \\
\hline & 4 & $0.000^{*}$ & $0.000 *$ & $0.000 *$ & $0.000 *$ \\
\hline \multirow{3}{*}{4} & 1 & $0.000 *$ & $0.000 *$ & $0.000 *$ & $0.000 *$ \\
\hline & 2 & $0.000 *$ & $0.000 *$ & $0.000 *$ & $0.000 *$ \\
\hline & 3 & $0.000 *$ & $0.000^{*}$ & $0.000^{*}$ & $0.000^{*}$ \\
\hline
\end{tabular}

*. The mean difference is significant at the 0.05 level

\section{Conclusion, implication and limitation}

The observation of alternate yield curve under this research has proven that there are better models compared to the official model; thus, could provide better fair pricing performance in the government bond areas. The in-sample valuations on the normal economic period has shown the Dynamic Nelson Siegel with $\lambda$ set at 0.077 value performed better compared with the other models. However, the Dynamic Nelson Siegel Svensson with Time Varying Loading followed the performance with comparably small gap i.e. less than 50 basis points in RMSE tracking. The DNS model provides simplicity in the process due to standard $\lambda$ that was being used in any point of time; yet generic number would face problem in the situation of volatile market in which we face in 2020. Due to this issue, the Dynamic Nelson Siegel Svensson with Time Varying Loading could be the other alternatives to perform in such dynamic market conditions.

In summary, the result of alternative model has practical implications for market participants in the bond market. The first implication is with the improvement in fair price performance, it would help market participants for their asset valuations, Central Bank and Government's Treasury for monetary, interest rate and borrowing decisions. The second implication lies in the improvement of overall maturity of Indonesia government bond yield curve, especially in medium and longer period. With more adaptive curve, it would help the government release bond with longer term maturity and therefore it could match with the long-term growth of the country economic planning. 
The limitation of this research is limited between 2014 until 2019 period of which considered as upward sloping curve or normal economic condition and limited to ten series of government bond. Therefore, we suggest to observe the model in more volatile financial market such as in crisis period such as financial crisis 2008-2010 and during Covid-19 pandemic in 2020. We also suggested in further research, the observation of static lambda that is based on Indonesia bond market would be beneficial in the Diebold Li model.

\section{References}

Bolder, D. \& Stréliski, D., (1999). Yield curve modelling at the bank of Canada. Bank of Canada Technical Report, 84.

Caceres, C. \& Unsal, F. (2013). Sovereign spreads and contagion risks in Asia. Asian Economic Journal, $27(3), 219-243$.

Castaño, R. M., Rueda, N. Z. \& Robayo, J. O. P. (2014). Dynamic estimation of an interest rate structure in Colombia. Empirical analysis using the Kalman filter. Journal of Economics, Finance and Administrative Science, 19, 70-77.

Cox, J. C., Ingersoll, J. E. \& Ross, S. A. (1985). A theory of the term structure of interest rates. Econometrica, 53(2), 385-407.

Dajcman, D. (2015). An empirical investigation of the nexus between Sovereign bonds yields and Stock Market Returns. Inzinerine Ekonomika-Engineering Economics, 26(2), 108-117.

Diebold , F. X. \& Li, C. (2006). Forecasting the term structure of government bond yields. Journal of Econometrics, 130(2), $337-364$.

Diebold, F. X., Rudebusch, G. D. \& Aruoba, B. S. (2007). The macroeconomy and the yield curve: A dynamic latent factor approach.. Journal of Econometrics, 131(1-2), 309-338.

Fisher, M., Nychka, D. \& Zervos, D. (1995). Fitting the term structure of interest rates with smoothing splines. Finance and Economics Discussion Series, Federal Reserve Board, Working Paper 95-101.

Giraldo, M. V., Betancur, J. C. G. \& Hurtado, P. M. A. (2016). Parameters calibration of the NS and NSS interest rates for Colombia: A technical note. Journal of Economics, Finance and Administrative Science, 21, 73-80.

Heath, D., Jarrow, R. \& Morton, A. (1992). Bond pricing and the term structure of interest rate: A new methodology for contingent claims valuation. Econometrics, 60(1), pp. 77-105.

Hull, J. \& White, A. (1990). Pricing interest rate derivative securities. The Review of Financial Studies, 3(4), $573-592$.

Krishnamurthy, A. \& Jorgensen, A. V. (2012). The aggregate demand for treasury debt. Journal of Political Economy, 120(2), 233-267.

McCulloch, H. J. (1971). Measuring the term structure of interest rates. The Journal of Business, 44, 19-31.

McCulloch, H. J. (1975). The tax-adjusted yield curve. The Journal of Finance, 30, 811-830.

Svensson, L. E. O. (1994). Estimating and Interpreting Forward Interest Rates: Sweden 1992-4. CEPR Discussion Paper Series, October(1051).

Ullah, W., Matsuda, Y. \& Tsukuda, Y. (2015). Generalized Nelson-Siegel term structure model: do the second slope and curvature factors improve the in-sample fit and out-of-sample forecasts?. Journal of Applied Statistics, 42(4), 876-904.

Vasicek, O. A. \& Fong, G. H. (1982). Term structure modelling using exponential splines. Journal of Finance, $37,339-348$.

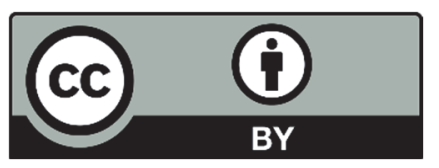

(C) 2020 by the authors; licensee Growing Science, Canada. This is an open access article distributed under the terms and conditions of the Creative Commons Attribution (CC-BY) license (http://creativecommons.org/licenses/by/4.0/). 